$\Rightarrow$

\section{Meet the ancestors}

DOI:

10.1038/nrmicro1667

\section{URLs}

Mycobacterium bovis

http://www.ncbi.nlm.

nih.gov/entrez/query.fc gi?db=genomeprj\&cmd $=$ Retrieve\&dopt $=$ Overv iew\&list_uids $=12311$

Mycobacterium tuberculosis

http://www.ncbi.nlm. nih.gov/entrez/query.fc gi? $\mathrm{db}=$ genomeprj\&cmd $=$ Retrieve $\&$ dopt $=$ Overv iew\&list_uids $=12318$
DNA evidence from ancient skeletal remains attests to the presence of tuberculosis in the earliest human societies. A recent study published in Microbiology describes the first report of Mycobacterium bovis DNA present in archaeological human remains. Furthermore, genotypic analysis of this DNA supports the evolutionary scenario that proposes M. bovis evolved from an ancestral Mycobacterium tuberculosis lineage.

Tuberculosis, which is caused by bacteria of the M. tuberculosis complex, is primarily a disease of the soft tissues but it can occasionally affect the skeleton. Earlier research established that under the right conditions, intact mycobacterial DNA could be amplified from bone material using PCR. Using this technology to analyse single-nucleotide polymorphic loci and genomic regions of differences $(\mathrm{RD})$ in the M. tuberculosis complex, the authors focused their attention on bone samples obtained from five Iron Age individuals with skeletal evidence of tuberculosis. Following successful amplification of mycobacterial DNA from four of the five samples, the DNA was subjected to genotyping PCR. This analysis revealed that RDs 12, 13 and 4 were all deleted whereas an $M$. tuberculosis specific deletion (known as TbD1) was still present. These findings, together with the nucleotide polymorphism analysis, indicate that all four cases were due to infection by $M$. bovis rather than $M$. tuberculosis, a finding that represents the first documented case of bovine tuberculosis in human remains. These data are also consistent with the evolutionary scheme that proposes $M$. bovis diverged from the progenitor of present day $M$. tuberculosis strains. In addition, the study confirms that classic M. bovis - defined in this scheme by the loss of RD4 - was present and was causing human infection at least 2,000 years ago.
The use of deletion analysis in conjunction with molecular typing and analysis of specific mutation profiles represents an undoubtedly powerful approach for the study of the tubercle bacillus. As demonstrated in this study, however, the application of this approach to DNA sampled from accurately dated archaeological tuberculosis cases represents a new tactic to further our understanding of the history and evolution of this ancient disease.

\section{David O'Connell}

ORIGINAL RESEARCH PAPER Taylor, G. M. et al. First report of Mycobacterium bovis DNA in human remains from the Iron Age. Microbiology 153, 1243-1249 (2007) FURTHER READING Drancourt, M. \& Raoult, D. Palaeomicrobiology: current issues and perspectives. Nature Rev. Microbiol. 3, 23-35 (2005)

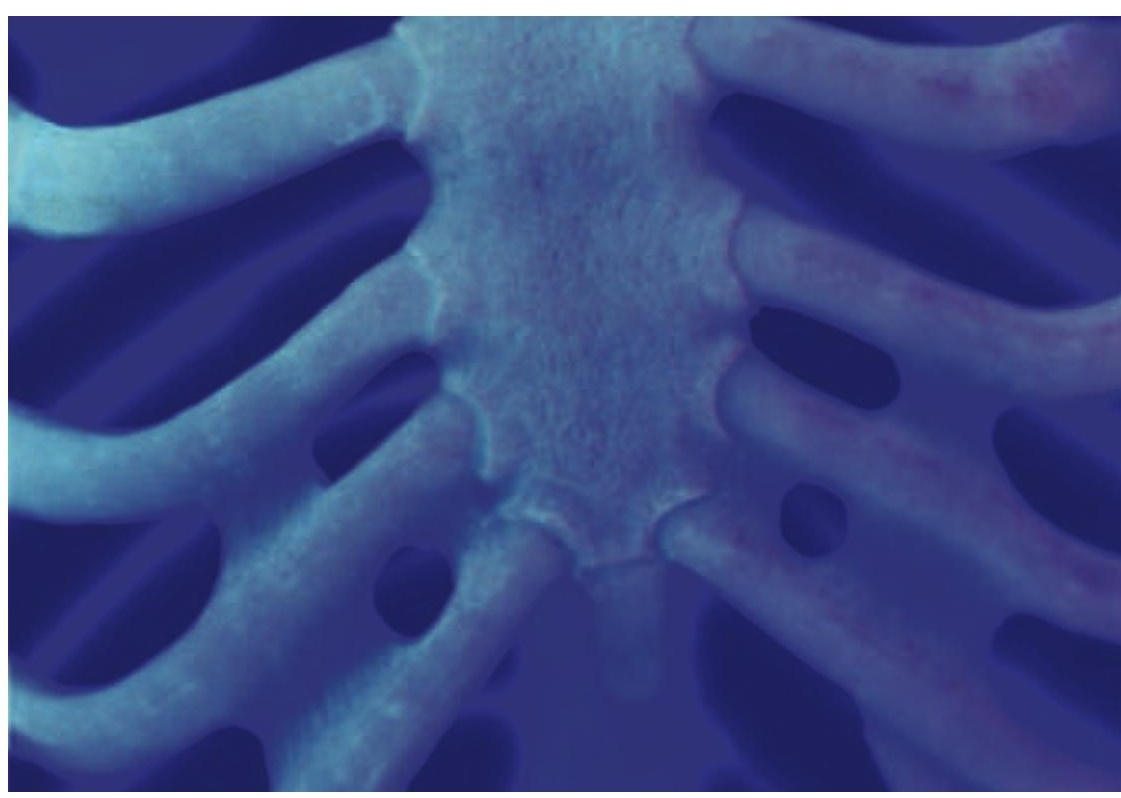

